\title{
Network Coordination In The Global Goods Flow : The Case Of Korea
}

\author{
Eon-seong Lee*, Ho-yeol Bang ${ }^{* * 1)}$
}

\begin{abstract}
Effectively managing an intermodal logistics network has become a significant strategic consideration in international logistics. This study aims to empirically examine the way in which intermodal logistics network coordination can be successfully developed and sustained, and to analyze whether the highly coordinated intermodal logistics network may facilitate the greater logistics performance of network players as well as of the entire intermodal logistic network system. This study adopts social network embeddedness perspective to examine the determinants facilitating the higher level of coordination of the intermodal logistics network. An explorative interview method is being employed for the empirical analysis, and the results show that strong, dense and bridging ties within the network mechanisms facilitate a greater intermodal logistics network coordination. As a result, this helps to enhance the logistics performance of the intermodal logistics network system and its players by facilitating the enhancement of logistics services effectiveness and operational efficiency.
\end{abstract}

Key Words: Intermodal Logistics Network, Coordination, Social Network Embeddedness, Logistics Performance

JEL codes: $M 16$

* Department of Maritime and Logistics Management, Australian Maritime College, University of Tasmania, Launceston, Australia. Email: EonSeong.Lee@utas.edu.au

** Department of Business Administration, Pusan National University, Busan, Korea. Email: hybang@pusan.ac.kr

1) Corresponding Author's Full Address: Ho-Yeol Bang, College of Business, Pusan National University Busandaehak-ro, 63Beon-gil, Geumjung-gu, Busan 609-735, Korea, Email: hybang@pusan.ac.kr 


\section{Introduction}

An intermodal logistics network system is referred to as "an integrated transportation system consisting of two or more modes" (Haasis 2008, p. 269). The intermodal logistics network (i.e. sea and land transport logistics networks in this research) may significantly affect the entire global logistics performance because it is an integrated part of the global logistics and supply chain. In this sense, effectively managing an intermodal logistics network has become a significant strategic consideration in global logistics (Paixao and Marlow, 2003). Previous studies have highlighted the fact that highly coordinated logistics activities contribute to a more efficient and effective logistics flow by facilitating a quicker, cheaper, and more flexible movement of cargoes (Panayides, 2002; Panayides and Song, 2005; Jayaraman et al., 2008; Bahinipati et al., 2009). Yet despite the significance of logistics coordination, few studies have empirically investigate key factors which determine a higher level of coordination of the intermodal logistics network nor have there been any attempts to clarify whether a highly coordinated intermodal logistics system can help improve the logistics performance of entities of the network. In order to fill this gap, this research aims (i) to identify the way in which intermodal logistics network coordination can be successfully developed and sustained, and (ii) to analyze whether the highly coordinated intermodal logistics network may facilitate the greater logistics performance of players in the network as well as of the entire network system.

So as to meet the aforementioned research goals, this paper applies a social network embeddedness perspective, which has been popularly used to examine how organisations can effectively coordinate inter-organisational relationships within a social network, and whether these highly coordinated relations may help to improve a firm's competitive advantages and organisational performance (Rowley et al., 2000). Thus, this theory could give significant insight into the inter-organisational coordination mechanism for an intermodal logistics network system.

This paper will discuss the following points. Firstly, the literature review will discuss the significance of intermodal logistics network coordination within the context of global logistics, and the inter-organisational mechanism of the network which facilitates successful coordination will be identified. Based on a critical review of the existing literature, a conceptual model that shows the positive relationship between interorganisaitonal network mechanism, intermodal logistics network coordination and logistics performance will be developed. The conceptual relations would be empirically analysed by using an interview method which is conducted in the intermodal logistics network established in Busan Port in Korea. This will be followed, finally, by the discussion and conclusion. 


\section{Theoretical Background}

\subsection{Coordination in Intermodal Logistics Network and Logistics Performance}

Coordination is referred to as two or more organisations that collaborate with competitors and/or non-competitors in the industry by sharing information, resources and tasks in order to achieve their common goals (Barratt, 2004; Simatupang and Sridharan, 2002). The successful coordination or integration of globally dispersed logistics activities1 has been one of the most significant strategic considerations in global logistics and supply chain management, because effectively aligning and coordinating globally dispersed logistics activities across the global supply chain is a fundamental task that global logistics managers should perform in order to maximise a logistics firm's performance (Song and Lee, 2012; Srikanth and Puranam, 2011). For instance, highly coordinated logistics functions would make it easier for the members to eliminate unnecessary activities that would duplicate or do not add value to the customer, and it would help the members to respond quickly to requirements of the customers (Waters, 1999). It may contribute to the reduction of operation costs - unlike a system in which individual entities operate separately or independently - and thereby improve firms' financial performance (Vickery et al., 2003). A highly coordinated logistics system would also allow logistics entities to deliver products to customers at the right time and right place in a more flexible and responsive manner (Narasimhan and Jayaram, 1998). We could apply this contention to intermodal logistics management, because an intermodal logistics network is an integrated part of global logistics (Mason and Lalwani, 2004). Therefore, a greater amount of coordination between intermodal logistics network entities would be essential to enhancing logistics value and performance of the firms.

\subsection{Resource and Task Sharing for Intermodal Logistics Network Coordination}

Coordination in global logistics management would be reflected by the extent to which the divided activities of logistics (e.g. parties in both the upstream and downstream of a logistics system) are collaborating effectively (Crowston, 1997; Srikanth and Puranam, 2011). It has been addressed that the successful process of global logistics coordination depends largely on the extent of resource and task sharing between the cooperating entities within a logistics chain to achieve their common business goals (Crowston, 1997; Srikanth and Puranam, 2011; Paixao and Marlow, 2003; Panayides and Song, 2008; Vickery et al., 
2003). Therefore, a high level of coordination within an intermodal logistics network would be reflected in greater resource and task sharing between players of the network.

With regard to the types of resources intermodal logistics operators share for greater intermodal logistics network coordination, we consider both tangible and intangible resources (Barney, 1986). For instance, shared resources such as facilities, equipments, information systems, and materials or assets, could be included in the tangible resources, and exchanged information or knowledge would be classified in the intangible resource categories (Lee and Song, 2010).

On the other hand, the tasks to be shared among intermodal logistics network entities would encompass various logistics activities, which are required to be done by intermodal logistics operators in a collaborative manner. For example, in order to ensure that the cargoes be moved flexibly to the next stage of the logistics flow and then to successfully be integrated into the global logistics flow, the intermodal logistics operators are required to share the various logistics services, such as pick-up service, delivery notification, a special handling service for customers that require particular service, inbound/outbound bill of lading $(\mathrm{B} / \mathrm{L})$, container tracking and information, warehousing, storage and packing, (Robinson, 2002; Carbone and de Martin, 2003; Bichou and Gray, 2004; Roh et al., 2007).

\subsection{Social Network Embeddedness for Intermodal Logistics Network Coordination}

A social network perspective has been considered as a critical coordination mechanism that facilitates resource and task sharing between organisations within a network (Gulati, 1999; McEvily and Zaheer, 1999). The coordination advantages of the social network may vary depending upon a firm's different position in a network (Burt, 1992; Gulati, 1999; McEvily and Zaheer, 1999; Rowley et al., 2000). This view has been referred to as the network embeddedness perspective. According to this, the different levels of a firm's position within a network engender different opportunities to access social capital such as knowledge, resource and work sharing across the firms; it also alters the network-based advantages, which then leads to different levels of a firm's performance (Burt, 1992; Uzzi, 1997). Network embeddedness perspective indicates two types of positioning mechanisms: structural and relational embeddedness (Gulati, 1999).

The structural embeddedness perspective acknowledges that the structure of social network ties affects opportunities to acquire external resources, and a firm which is embedded in a superior position in a network can gain more social capital (Burt, 1992). There are some key variables of structural embeddedness such as network density and the structural hole. The network density is referred to as the extent to which the ties among the 
actors are inter-connected in a network (Grantovetter, 1973). We can apply the network density concept to intermodal logistics network practices. An intermodal logistics network consists of multiply linked firms in sea and land transportation, within which the entities would be linked through vertical (i.e. buyer - supplier relationship) or horizontal (i.e. competitors operating in the same business) relationships. Firms which are densely embedded in a network by having as many ties as possible would be in a superior position to access various resource and tasks (Gulati, 1999; McEvily and Zaheer, 2001). Therefore, a higher network density would give firms in an intermodal logistics network more opportunities for greater resource and task sharing.

Another coordination mechanism of network structural embeddedness is 'bridging ties'. A structural hole is referred to as the gaps between firms otherwise disconnected in the network (Burt, 1992). Burt (1992) developed a 'bridging tie' terminology, which means the practice when a focal firm spans structural holes in a network. The bridging of structural holes would facilitate resource and task sharing among the firms within a network because it connects firms in the network although they have not been directly linked (But, 1992; McEvily and Zaheer, 2001). This argument may validate the proposition that bridging ties would help a focal firm in an intermodal logistics network to be superior to access more opportunities to network capital and as a result it would facilitate greater resource and task sharing between the network players (Gulati, 1999).

The other network embeddedness mechanism is relational embeddedness. Tie strength is the most important indicator of relational network embeddedness (Uzzi 1997; Rowley et al., 2000), and it is defined as "a combination of the amount of time, the emotional intensity, the intimacy, and the reciprocal services which characterise the tie" (Granovetter, 1973, p. 1361). There is a contention that strong ties have the following notable benefits on resource and task sharing within a network. Firstly, keeping strong relations would enable the entities to establish mutual trust between organisations, and this then facilitates the exchange of valuable resources and information that are themselves difficult to acquire from an arm's-length transaction (Uzzi, 1997). Secondly, strong and close ties can promote in-depth and more open communication. This allows actors to share knowledge that is more tacit, which could not be easily transferred unless the actors are not close to each other (Uzzi, 1997). In addition, this would enable the actors to respond to each other's needs more quickly and appropriately, which helps to effectively and efficiently coordinate the different tasks of all the actors (Uzzi, 1997). These contentions may ensure that if intermodal logistics network operators keep strong relations with other operators, they will trust each other more and would be more proactive in sharing resources and tasks; this, consequently, would increase the coordination related synergy effect. 
The aforementioned theoretical discussion about intermodal logistics network embeddedness, resource and tasks sharing and intermodal logistics performance is depicted in Figure 1.

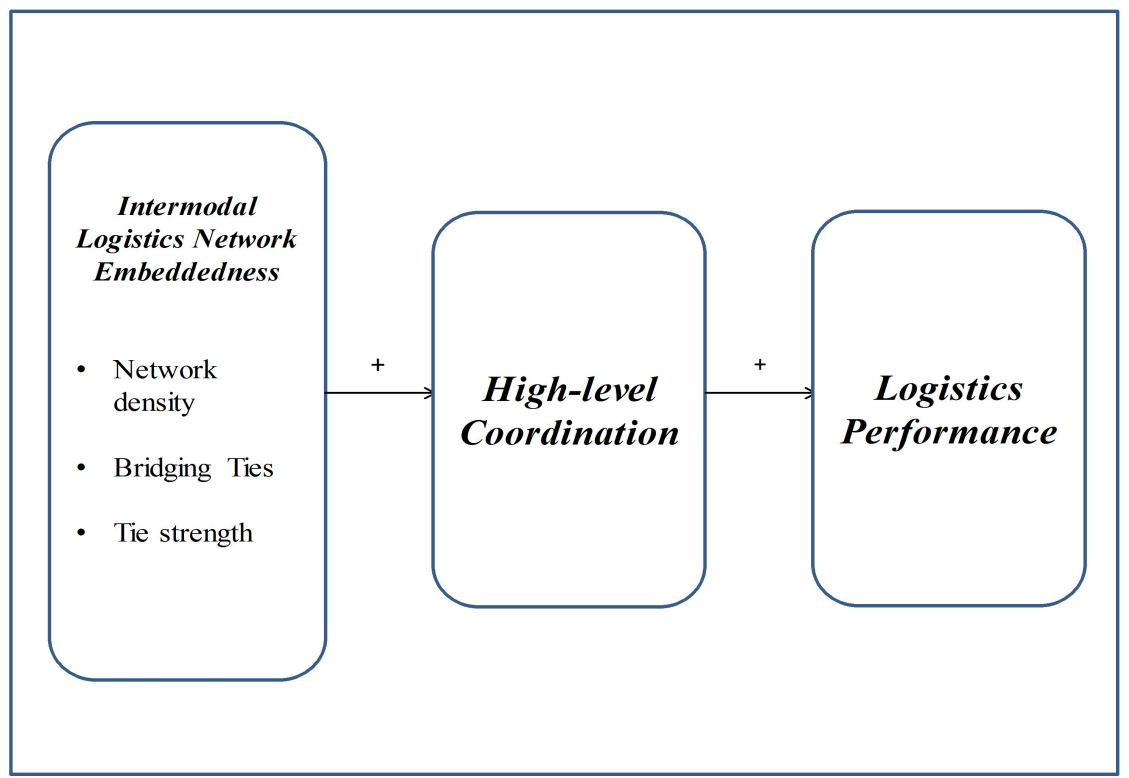

Figure 1.

Conceptual Framework

\section{Research Method}

This study employs an explorative qualitative method, i.e. a small scale exploratory interview method. Explorative interview methods are widely used to explore little known issues and identify the relevant patterns that have occurred in the field by allowing researchers to collect data in which selected participants freely express their opinions, thoughts or beliefs on the current research problems (Song and Lee, 2012). Therefore, the explorative interview method would be useful for this study in exploring the general patterns about the proposed conceptual relationship by reflecting the subjective opinions of company managers and specialists in the intermodal logistics industry on the current research issue. With regard to a geographical scope of this research, the Korean intermodal industry, in particular the intermodal logistics network established in Busan Port in Korea, was chosen for the empirical analysis, since the strategic significance of Busan Port as a 
key logistics centre in Asia has steadily increased as it ranks fifth in the world in terms of ports, its intermodal logistics system has been recognised as being very efficient and successful.

For the explorative interview method, a semi-structured face-to-face interview with an open-ended questionnaire was conducted, and a total of ten interviewees from intermodal logistics operators, researchers and policy makers involved in the Busan Port intermodal logistics industry participated in the interview. The empirical analysis has focused merely on the sea and road intermodal transport logistics flows. This is because the rail transportation, which is connected to the sea transportation both inbound and outbound of Busan Port, accounts for very small ratio, only less than ten percent out of the total, whilst the road transportation makes up over ninety percent of the total. The interviewees were selected from companies that included shipping companies, freight forwarders, port terminal operators and road transport operator, and are themselves all specialists in the Busan Port intermodal logistics industry. The selected companies are some of the most prominent companies in the industry, having a healthy financial structure and good reputation in the Busan Port intermodal logistics industry. A brief profile of each of the companies that consented to the interview is described in Table 1.

\section{Table 1.}

Profiles of the Interviewed Companies

\begin{tabular}{c|c|c}
\hline \multirow{2}{*}{ Type of Company } & Title of the Interviewee & Types of Business Origin \\
\hline \multirow{2}{*}{ Port Terminal Operators } & CEO & General port-terminal operations \\
\cline { 2 - 3 } & $\begin{array}{c}\text { General Manager/ Container } \\
\text { Business Team }\end{array}$ & General port-terminal operations \\
\cline { 2 - 3 } Freight forwarders & General Manager/ Planning Team & Busan Port Authority \\
\cline { 2 - 3 } Shipping companies & Ceneal Manager/Marketing Team & International freight forwarding \\
\cline { 2 - 3 } & General Manager/Marketing Team & $\begin{array}{c}\text { International freight forwarding } \\
\text { container cargoes by ships }\end{array}$ \\
\hline Road transport operator & General Manager & $\begin{array}{c}\text { International sea transport of } \\
\text { container cargoes by ships }\end{array}$ \\
\hline $\begin{array}{c}\text { Busan } \\
\text { Development Institute }\end{array}$ & Chief Researcher & $\begin{array}{c}\text { Governmental research and } \\
\text { policy institute for Busan } \\
\text { Development }\end{array}$ \\
\hline $\begin{array}{c}\text { Busan Metropolitan } \\
\text { Government }\end{array}$ & Specialist & $\begin{array}{c}\text { Port Logistics Division } \\
\text { Busan Metropolitan City }\end{array}$ \\
\hline
\end{tabular}


The interviewees from these companies are the presidents or general managers from each company, those who have a rich knowledge of their operations and strategies and can discuss the research questions while simultaneously providing a wide range of insight into the overall market situations in the industry. The specialists are the experts and policy makers who work in leading research centers under government institutions in the maritime and intermodal logistics field. After performing the pre-test with the participation of two practitioners, the main interview was then conducted in January 2013. Four of the interviews were digital recorded, but the others refused due to both confidentiality and personal reasons. Each interview lasted between 40 and 100 minutes.

\section{Findings}

The empirical results consist of the following two parts: intermodal logistics network embeddedness and coordination, and its impact on logistics performance. The findings from the explorative study are presented based on the subjective answers of the interviewees.

\subsection{Intermodal Logistics Network Embeddedness and Coordination}

The interviewees were initially given an explanation of the concept of intermodal logistics networks, coordination and logistics performance. The interviewees were asked to think of one intermodal logistics network in which their company is involved and then answer the interview questions relating to their particular network. In the case that their company was involved in more than one intermodal logistics network, they were asked to think of the one that they consider as being most significant to their company's logistics activities.

The intermodal logistics network tie was measured as the linkage which is connected with other players in the network in forms of inter-firm transaction relationships as a buyer and service provider, or inter-firm cooperating relationships either formally such as contract-based cooperation e.g. strategic alliance, marketing agreements, etc., or informally such as inter-firm associations, informal meetings or contacts between employees. The tie strength between the network players was explored by asking the following aspects: the extent of how frequently your company keeps in touch with other companies with which they are linked; the extent to which your company respects the other companies' opinions when making common business decisions; the extent to which your company considers the transacting companies to be very important to both your business and mutual interests; and 
the extent to which your company believes the transacting companies will not cheat your company (Uzzi, 1997; Yi-Renko et al., 2001).

The answers from the interviewees show that they are generally establishing strong and close relationships with other entities within the intermodal logistics network, in that they frequently contact with each other through emails, telephones and/or formal or informal meetings, respect to each others and regard their transacting companies as very important for their mutual interests.

With regard to the extent of the number of ties which intermodal logistic network players have, all the interviewees were asked whether their respective companies have a great number of ties in the intermodal logistics network, and how many companies, approximately, are connected with each other in the network. Although the interviewees could not provide approximate numbers of the connected ties, all of the interviewees agreed that they are all generally densely connected with other companies in the intermodal logistics network, in that they are transacting or cooperating with other network players as many ways as they can, in order to perform the logistics activities more effectively and efficiently.

The last network embeddedness issue is about bridging ties. The issue of bridging ties was investigated by asking whether a focal company can span a structural hole by connecting other companies which are linked with the focal company but don't have direct ties between themselves. The interviewees addressed that they often, when necessary, play a bridging role in introducing companies to one another. For example, when freight forwarders have to handle excessive cargoes during peak season and are unable to deal with this cargo with their capacity, they often seek other companies to handle the excessive goods in their place. In the event that the initial company asked is still unable to handle the excessive cargoes, the focal company will introduce their customers to another third company which has spare capacity to deal with the cargo. These practices, therefore, indicate the prevalence of a focal company's bridging ties between both their transacting company and the other, third-party company.

In order to investigate the impact of the network embeddedness on the intermodal logistics network coordination, the interviewees were asked whether and how the tie strengths, the numbers, and the bridging ties themselves can facilitate resource and/or tasks sharing between the companies in the networks. All of the interviewees expressed the similar opinion that greater numbers of and stronger relationships with other companies in the network promote effective resources and tasks sharing. As a result, this helps the players to cooperate and work together effectively. Most of the interviewees said that, as they have more cooperators and transactions in the network and keep those relations closer, they could interact with various companies, could establish stronger mutual trusts with 
other players, could exchange more useful resources and information, and could therefore share a lot of works so as to make cargoes move more quickly and efficiently. These results would support the previous contentions which highlight the relational benefits acquired from strong and dense ties (Uzzi, 1997; McEvily and Zaheer, 2001).

The interviewees also addressed the positive impact of bridging ties on resource and task sharing between the companies in the intermodal logistics network. For example, as we have seen before, companies in the network often introduce and/or are introduced by other companies in order to correspond to excessive works, and it was revealed that these practices have helped insofar as they allow companies to proactively share useful information or knowledge as well as related tasks. According to an interviewee, the prospect of bridging ties is also helpful in improving mutual interests of the cooperating companies, because the company that gives excessive cargoes to the third company could fulfill their customers' needs immediately without any delays by receiving the other company's assistance, and they might also expect the similar benefits from the other companies in the future. These practices reveal that firms' bridging ties would facilitate both resource and task sharing advantages between firms in the network because it may allow them superior access to information. This result also supports existing contentions (Burt, 1992; McEvily and Zaheer, 2001).

The above interview results are consistent with previous evidence which states that the extent of strong, high numbers of and bridging ties in the intermodal logistics network may facilitate vigorous resource and task sharing between organisations and therefore determine the higher level of inter-firm coordination (Krackhardt, 1992; Uzzi, 1997). Having these empirical findings in mind, this paper suggests the following propositions:

Proposition 1 : The extent of relational and structural embeddedness among players within an intermodal logistic network is positively associated with the level of inter-firm coordination of the network.

$\boldsymbol{P}_{1 a}:$ A great number of ties in an its intermodal logistics network may facilitate great resource and task sharing with other players in the network.

$\boldsymbol{P}_{1 b}$ : The strong ties that a company has in its intermodal logistics network may facilitate greater resource and task sharing with other players in the network. 
$\boldsymbol{P}_{1 c}$ : Bridging ties between companies in its intermodal logistics network may facilitate a given company's great resource and task sharing with other players in the network

\subsection{Network Coordination and Logistics Performance}

As a final part of the interview, the effect of a high level of inter-firm coordination on the logistics performance was explored by asking all the interviewees these questions: "What is your view on the idea that resource and task sharing with other companies in the intermodal logistics network would help your company and other companies in the network to improve logistics performance, e.g. improvement of service quality (e.g. service responsiveness, flexibility, reliability and safety) and operational efficiency (e.g. reduction of lead time and business costs), thereby contributing to the improvement of logistics performance of the entire network?" All the interviewees agreed the positive influence of resource and task sharing on the enhancement of the logistics performance, both for individual entities as well as the entire network. Looking at the answers carefully, one interviewee from a port terminal operator mentioned that:

"We could make best use of the shared resources such as some facilities or equipments, and it helps to reduce our costs and time, as well as to respond to our customer's demands flexibly. We also share many tasks with other operators in our logistics network, such as storing and handling cargoes, empty containers handling with warehousing companies and shipping companies. I am confident that this resource and task sharing would definitely facilitate the improvement in our service quality, such as increased customer responsiveness, service flexibility and reliability, work productivity, and the reduction of the lead time and business costs. In addition, it would certainly be true that these advantages would eventually lead to the enhancement of the system efficiency and service quality of the entire intermodal logistics services in Busan Port."

The interviewees also addressed additional benefits of a high level of coordination by mentioning that the resource and tasks sharing have enabled them to communicate more openly and made their relations more mutually dependent. This has facilitated the development of useful device or data processing routines in order to jointly solve business problems which they may all have in common. In addition, as they share more information, they could increasingly understand other companies' various business situations and practices, and better work together by adjusting themselves in a more collaborative and 
flexible manner. This helps them to identify and eliminate duplicated works or wasteful activities, as well as to avoid unnecessary conflicts, and to compromise their own interests for their common goal, i.e. maximisation of the performance of the entire logistics system wherein they belong. As a result, they think that the successful coordination of intermodal logistics network entities would be crucial in enabling them to realise a higher level of logistics performance, not only for their individual company but also for efficiency of the entire network system.

The above answers reveal that resource and task sharing helps to reduce lead time and costs, and from there helps to improve service effectiveness. Therefore, it is believed that the high level of coordination of an intermodal logistics network may have a strong positive influence on the enhancement of the logistics performance of individual companies in the network, as well as the integrated services of the entire logistics network. This positive relationship is consistent with previous studies which highlight the effectiveness of highly coordinated inter-organisational relationships realised throughout resource and task sharing on the improvement of the service quality of logistics firms (Jahre and Jensen, 2010; Panayides, 2002), organisational efficiency and effectiveness (Yli-Renko et al. 2001), and market performance within a supply chain (Christensen et al., 2005). From these results, the following proposition may be suggested.

Proposition 2: A higher level of coordination in the intermodal logistics network is positively associated with the improvement of the logistics performance of the logistics firms and the entire network.

\section{Discussion and Conclusions}

The purpose of this study is to examine the significance of inter-organisational coordination mechanism in successfully managing intermodal logistics activities, and to investigate how the greater intermodal logistics network coordination can be realised and whether the coordination really helps to maximise the logistics performance of the firms within the network as well as the entire network. The theoretical basis for this argument are social network embeddedness theories, which are themselves engaged in organisational coordination mechanism and its subsequent impact on the enhancement of firms' performance.

The results of empirical analysis show that companies within an intermodal logistics network in Busan Port are establishing high numbers of strong ties with each other at both 
vertical and horizontal level, and these strong and dense ties facilitate the greater sharing of resources and tasks among the companies. We also explored the role of bridging ties in promoting intermodal logistics network coordination. It has been revealed that the companies in the network have gained a lot of benefits from bridging ties, as a focal firm and other actors could share resources and tasks with each other through having the focal firm proactively connect other actors separated by a structural hole. The bridging ties have spanned the structural holes variously between the companies at both vertical and horizontal areas, and the bridging ties would have enabled access to new and diverse information as well as to new business opportunities.

The results of this research also indicate that a higher level of coordination of an intermodal logistics network would be positively related to the enhancement of the logistics performance of the individual firms in the network, as well as the entire network, through promoting the improvement of customer service and the reduction of time and costs. Many of previous works ensure that successful coordination of the market participants contributes to the reduction of costs, price and operational time (i.e. efficiency) and the enhancement of firms' responsiveness, flexibility and reliability (i.e. effectiveness) (Vickery et al., 2003; Chen et al., 2004). Thus, the findings of this study support the previous contentions, and therefore ensure that successful inter-organisational coordination through greater resource and task sharing between players would be a key strategic tool in moving towards the greater operational efficiency and higher level of service quality of intermodal logistics network.

This paper may provide meaningful strategic insight for the managers of logistics companies involved in the maritime and land transport industry, in terms of how they strategically manage the inter-organisational relationships within an intermodal logistics network in order to share more resource in particular knowledge and tasks so as to become a more integrated system. This paper also encourages managers to think more broadly about their managerial direction, and shift their thinking towards a more holistic approach, i.e. the integration of intermodal logistics network, rather than focusing solely on their own independent operations (Lee, 2012). Nevertheless, the arguments of this paper are solely explorative and qualitative in their research method. Being based on the qualitative results of this paper, future research may develop relevant hypotheses about the coordination mechanisms of intermodal logistics networks and their impact on logistics performance; and the hypotheses can be statistically tested by the usage of a quantitative research method. In addition, the geographical scope of this paper focuses merely on Busan Port in Korea. This therefore brings about limitations regarding generalisations of the empirical results. This limitation could be overcome, however, if future research looks to expand the regional scope of data collection to other countries, where the strategic importance of 
intermodal logistics becomes greater (Song and Lee, 2012).

Note

1. As the concepts of coordination, collaboration and integration have been often used interchangeably in logistics and business management (Jahre and Jensen, 2010; Fabbe-Costes and Jahre, 2006, 2008; van Wasenhove, 2006), this paper accordingly follows this view. An extensive review to differentiate those concepts is beyond this paper, and it would remain to be clarified in the future research.

\section{Acknowledgement}

The authors wish to convey their gratitude to the interview participants for their professionalism, and for their valuable insights into the line of research on which the current paper is developed. They are also thankful for the support of the Center for International Exchange \& Cooperation on Shipping, Port and International Logistics founded by the Ministry of Land, Transport and Maritime Affairs in Korea. 


\section{References}

Bahinipati, B. K., Kanda, A. and Deshmukh, S. G. (2009) "Coordinated Supply Management: Review, Insights, and Limitations", International Journal of Logistics: Research and Applications, 12(6), 407-422.

Barney, J. B. (1986) "Strategic Factor Markets: Expectations, Luck, and Business Strategy", Management Science, 32, 1231-1241.

Barratt, M. (2004) "Understanding the Meaning of Collaboration in the Supply Chain", Supply Chain Management: An International Journal, 9(1), 30-42.

Bichou, K. and Gray, R. (2004) "A Logistics and Supply Chain Management Approach to Port Performance Measurement”, Maritime Policy and Management, 31(1), 47-67.

Burt, R. S. (1992) Structural Holes: The Social Structure of Competition, Harvard University Press, Boston.

Carbone, V. and De Martine, M. (2003) "The Changing Role of Ports in Supply-chain Management: an Empirical Analysis", Maritime Policy and Management, 30(4), 305-320.

Christensen,W., Germain, R. and Birou, L. (2007) "Variance vs. Average: Supply Chain Lead-time as a Predictor of Financial Performance", Supply Chain Management: An International Journal, 12 (5), 349-57.

Crowston, K. (1997) “A Coordination Theory Approach to Organizational Process Design”, Organization Science, 8(2), pp. 157-175.

Fabbe-Costes, N. and Jahre, M. (2007) "Supply Chain Integration Improves Performance: the Emperor's New Suit", International Journal of Physical Distribution and Logistics Management, 37(10), 835-855.

Grantovetter, M. (1973) "The Strength of Weak Ties", American Journal of Sociology, 78(5), 1360-1380. 
Gulati, R. (1999) "Network Location and Learning: the Influence of Network Resources and Firm Capabilities on Alliance Formation", Strategic Management Journal, 20(5), 397-420.

Haasis, H. D. (2008), "Knowledge Management in Intermodal Logistics Networks", In Haasis, H.D., Kreowski, H. J. and Sholz-Reither, B. (eds.) Dynamics in Logistics. Springer, Berlin.

Jahre, M. and Jensen, L. (2010) "Coordination in Humanitarian Logistics through Clusters", International Journal of Physical Distribution \& Logistics Management, 40(8/9), 6578-674.

Jayaraman, V., Ross, A. D. and Agarwal, A. (2008) "Role of Information Technology and Collaboration in Reverse Logistics Supply Chains", International Journal of Logistics: Research and Applications, 11(6), 409-425.

Krackhardt, D. (1992) "The Strength of Strong Ties: the Importance of Philos in Organizations". In Nohria, N. and Eccles, R. (eds.), Networks and Organizations: Structure, Form, and Action, Harvard Business School Press, Boston, pp. 216-239.

Lee, E-S. (2012) "Knowledge Exchange and Intermodal Logistics Network Integration: Social Network Embeddedness Perspective", Journal of International Logistics and Trade, 10(2), 3-19.

Lee, E-S. and Song, D-W. (2010) "Knowledge Management for Maritime Logistics Value: Discussing Conceptual Issues", Maritime Policy and Management, 37(6), 563-583.

Mason, R. and Lalwani, C. (2004) "Integrating Transport into the Supply Chain to Improve Supply Chain Performance”, In Lalwani, C., Mason, R., Potter, A. and Yang, B. (eds.), Transport in Supply Chain, Logistics and Operation Management Section, Cardiff Business School, Cardiff, pp. 13-20.

McEvily, B. and Zaheer, A. (1999) "Bridging Ties: A Source of Firm Heterogeneity in Competitive Capabilities", Strategic Management Journal, 20(12), 1133-1156. 
Narasimhan, R. and Jayaram, J. (1998) "Causal Linkages in Supply Chain Management: An Exploratory Study of North American Manufacturing Firms", Decision Sciences, 29(3), 579-605.

Panayides, P. M. (2002) "Economic Organization of Intermodal Transport", Transport Reviews, 22(4), 401-414.

Panayides, P. M. and Song, D-W. (2008) "Evaluating the Integration of Seaport Container Terminals in Supply Chains" International Journal of Physical Distribution and Logistics Management, 38(7), pp. 562-584.

Paixao, A. C. and Marlow, P. B. (2003) "Fourth Generation Ports - A Question of Agility?", International Journal of Physical Distribution and Logistics Management, 33(4), 355-376.

Robinson, R. (2002) "Ports as Elements in Value-driven Chain Systems: the New Paradigm", Maritime Policy and Management, 29(3), 241-255.

Rowley, T., Behrens, D. and Krackhardt, D. (2000) "Redundant Governance Structures: An Analysis of Structural and Relational Embeddedness in the Steel and Semiconductor Industries", Strategic Management Journal, 21(3), 369-386.

Simatupang, T. M., and Sridharan, R. (2002) "The Collaborative Supply Chain" International Journal of Logistics Management, 13(1), 15-30.

Song, D-W. and Lee, E-S. (2012) "Coopetitive Networks, Knowledge Acquisition and Maritime Logistics Value", International Journal of Logistics: Research and Applications, 15(1), 15-35.

Srikanth, K. and Puranam, P. (2011) "Integrating Distributed Work: Comparing Task Design, Communication, and Tacit Coordination Mechanism", Strategic Management Journal, 32, 849-875.

Vickery, S. K., Jayaram. J., Droge, C. and Calantone, R. (2003) "The Effects of an Integrative Supply Chain Strategy on Customer Service and Financial Performance: An Analysis of Direct versus Indirect Relationships", Journal of Operations Management, 21(4), 523-539. 
Uzzi, B. (1997) "Social Structure and Competition in Interfirm Networks: the Paradox of Embeddedness", Administrative Science Quarterly, 42(2), 35-67.

Valente, T. W. (1995) Network Models of the Diffusion of Innovation, Hampton Press, New Jersey.

Van Wassenhove, L. N. (2006) "Humanitarian Aid Logistics: Supply Chain Management in High Gear", The Journal of Operations Research Society, 57(7), 475-89.

Waters, D. (2003) Logistics: An Introduction to Supply Chain Management, Palgrave, London.

Yi-Renko, H., Autio, E. and Sapienza, H. J. (2001) "Social Capital, Knowledge Acquisition and Knowledge Exploitation in Young Technology-based Firms", Strategic Management Journal, 22(6), 587-613. 